\title{
Wajdi Mouawad, Je t'embrasse pour finir
}

\section{Veronica Amadessi}

\section{(2) OpenEdition}

\section{Journals}

\section{Édition électronique}

URL : http://journals.openedition.org/studifrancesi/8416

DOI : ERREUR PDO dans /localdata/www-bin/Core/Core/Db/Db.class.php L.34 : SQLSTATE[HYO00]

[2006] MySQL server has gone away

ISSN : 2421-5856

\section{Éditeur}

Rosenberg \& Sellier

\section{Édition imprimée}

Date de publication : 1 mai 2009

Pagination : 222-223

ISSN : 0039-2944

\section{Référence électronique}

Veronica Amadessi, « Wajdi Mouawad, Je t'embrasse pour finir », Studi Francesi [En ligne], 157 (LIII | I) | 2009, mis en ligne le 30 novembre 2015, consulté le 07 janvier 2021. URL : http://

journals.openedition.org/studifrancesi/8416 ; DOI : https://doi.org/10.4000/studifrancesi.8416

Ce document a été généré automatiquement le 7 janvier 2021.

\section{(c) (i) (2)}

Studi Francesi è distribuita con Licenza Creative Commons Attribuzione - Non commerciale - Non opere derivate 4.0 Internazionale. 


\title{
Wajdi Mouawad, Je t'embrasse pour finir
}

\author{
Veronica Amadessi
}

\section{RÉFÉRENCE}

WAJDI MOUAWAD, Je t'embrasse pour finir, in Pour une littérature-monde, sous la direction de Michel LE BRIS et Jean ROUAUD, Paris, Gallimard, 2007, pp. 342.

1 Ce récit s'insère dans le remarquable recueil qui voit, entre autres, les contributions d'Alain Mabanckou, d'Édouard Glissant, d'Anna Moï et de plusieurs grands noms de la littérature contemporaine (prix littéraires). L'honneur est donc aux écrivains francophones, riche «constellation» détachée d'une nation qui n'a pour frontières que celles de l'esprit. En particulier, le texte inédit de Wajdi Mouawad paraît soulever, avec la grande sensibilité qui lui est propre, des questions qui circulent depuis longtemps dans le domaine de la francophonie en offrant toutefois une perspective nouvelle.

2 La lecture de ce récit d'une vingtaine de pages donne tout de suite au lecteur l'impression de bien connaître l'auteur libano-québécois. Les détails sur son enfance qu'il glisse dans le texte permettent immédiatement de prendre conscience du fait que deux aspects fondamentaux charpentent son écriture: l'errance et la langue. L'errance d'abord, puisque, dans le récit, le jeune narrateur voyage pour son travail. Bien avant, quand il était enfant, ses déplacements étaient dus à la guerre, au conflit civil qui poussa ses parents à quitter le Liban pour la France et ensuite le Canada. Ces nombreux exils ont entraîné à la fois la perte de la langue paternelle, dont il ne garde «aucun souvenir», et l'assimilation de la langue française, devenue sa première langue. Le changement d'espace a donc provoqué un déracinement aussi bien physique que psychologique, créant une énorme fracture dans l'identité du narrateur. La force du récit de Mouawad tient dans sa capacité de décrire une catastrophe personnelle au moyen d'un langage simple qui sait reconstituer des scènes quotidiennes avec une exactitude à la fois amusante et désarmante. Les conversations avec le père, le souvenir 
de l'apprentissage du français avec le grand frère constituent alors des exemples suffisamment évocateurs qui ne nécessitent pas d'explications. Mais la réflexion sur la langue se creuse et se teinte de nuances: la langue est considérée comme salvatrice; elle est l'instrument qui permet à l'auteur de s'intégrer dans un nouveau pays, «oasis au milieu du désert». Et dans tout cela, l'écriture peut redonner un sens aux choses: celle qui fait sortir l'enfant d'autrefois de son silence, mais qui sait aussi devenir une arme avec laquelle on peut mener des batailles. À elle se mêlent aussi l'écriture attentionnée et affectueuse du père, à travers le courrier électronique, et l'écriture du récit qui, finalement, réunit deux voix qui ne parlent plus la même langue. Les écrivains ayant vécu l'exil soulignent souvent cette problématique de la langue, mais ce récit possède la particularité de rendre hommage en même temps à un père qui «embrasse très fort» et à un travail qui est une vraie vocation («L'écriture comme acte de résistance de soi contre soi»). La narration, qui alterne des souvenirs heureux aux incertitudes et aux problèmes du présent, reste tendre et touchante, même si écrire consiste un peu à "porter le massacre avec des mots». 